\title{
Paramagnetic Centers Localized on a Phosphorus Ion in Gamma-Irradiated Metaphosphate Glasses
}

\author{
Hideo HOSONO and Yoshihiro ABE \\ ( $\begin{aligned} & \text { Department of Inorganic Materials, Nagoya Institute of Technology } \\ & \text { Gokiso-cho, Showa-ku, Nagoya-shi } 466\end{aligned}$
}

Radiation-induced paramagnetic centers whose unpaired electron is localized on a phosphorus ion were investigated with ESR in glassy and polycrystalline metaphosphates. Hyperfine doublet absorptions due to a ${ }^{31} \mathrm{P}$ nucleus with a separation of $70-120 \mathrm{mT}$ were analyzed.

The mean values and fluctuation widths of ESR parameters for the centers in the glasses were determined by the lineshape simulation of the observed spectra. The results obtained are summarized as follows:

( 1 ) $\mathrm{A} \mathrm{P}^{4+}$ center having fourfold coordination was observed in the as-irradiated $(77 \mathrm{~K})$ glassy and polycrystalline hosts. This center is considered to be derived from a $\mathrm{PO}_{4}^{2-}$ unit on capturing an electron. ( 2 ) On thermal annealing of as-irradiated glasses, the above center is converted into a $\mathrm{P}^{4+}$ center having threefold coordination of $\mathrm{C}_{3 \mathrm{v}}$ symmetry, detaching an oxygen from its coordination sphere. The resulting defect center is an analogue of $\mathrm{Si} \mathrm{E}^{\prime}$-center, the unpaired electron occupying a non-bonding level which is exclusively composed of $\mathrm{sp}^{3}$ hybrid orbital of phosphorus. (3) The formation of the fourfold-coordinated center and its thermal relaxation into the threefold-coordinated one are identical with the results of $\mathrm{As}(\mathrm{V})$ which has an electronic configuration analogous to $\mathrm{P}(\mathrm{V})$. It is suggested that these results are the common characteristics of $\mathrm{NWF}^{\prime} \mathrm{s}$ which belong to the $\mathrm{V}$ group on the periodic table. This fact may be ascribed to that these NWF's provide a coulombic potential for an electron trapping because their valence is greater than its coordination number.

[Received June 11, 1984]

\section{ガンマ線照射メタリン酸塩ガラス中のリン上に局在した 常磁性中心}

\author{
細野秀雄・阿部良弘 \\ (名古屋工業大学 無機材料工学科)
}

ガンマ線を照射したガラス状及び多結晶メタリン酸塩中の不対電子がリン上に局在する放射線誘 起常磁性中心を ESR を用いて調べた。 ${ }^{31} \mathrm{P}$ 核による $70 \sim 120 \mathrm{mT}$ の分離をもつ一対の超微細構造 の線形を解析した。ガラス中に生成した中心の ESR パラメーターの平均值とそのゆらぎはガラス 中の構造の分布を考慮した実測線形のシミュレーションによって決定した．得られた結果は以下の ようにまとめられる.

（1） 4 配位の $\mathrm{P}^{4+}$ 中心が $77 \mathrm{~K}$ で照射されたままのガラス及び多結晶中で観測された.この中

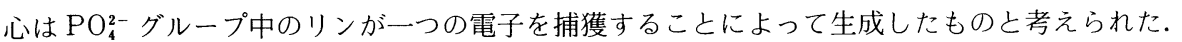

（2） $77 \mathrm{~K}$ で照射されたガラスを昇温すると，上記の中心は酸素を一つその配位球から放逐す ることによって $\mathrm{C}_{3 \mathrm{v}}$ に近い対称性をもつ 3 配位中心に転化した. その結果，生成した中心は $\mathrm{SiO}_{2}$ 中のいわゆる “E”-中心”に類似であり，不対電子はほとんどリンの $\mathrm{sp}^{3}$ 混成軌道からなる非結合 性準位を占有する.

（３）４配位中心の生成及びその 3 配位中心への構造の熱的緩和は相似の電子配置を有する As 
(V) と類似であり，これらの性質は 5 価の NWF の放射線誘起常磁性中心に固有の特徴であるこ とが示唆された。これは 5 価の NWF は原子価がその配位数よりも大きいので電子捕獲のための クーロン・ポテンシャルをもつことによると考えられた.

(1984 年 6 月 11 日受付)

Key-words: Phosphate glasses, Radiation, Paramagnetic defects, ESR, Radiochemical reaction

\section{Introduction}

On exposure to energetic photons such as UV, $\mathrm{X}$ or $\gamma$-rays, trapped electron and trapped ho-le centers are produced in most glasses by radiochemical reaction. Since the energy levels of these radiation-induced centers are generally located in the band gap, new optical absorption bands appear in an energy region lower than the original absorption edge. Some optical properties of host glasses are modified by these induced bands. Radiation-induced optical attenuation of fiber optics materials is a typical example ${ }^{1}$. In some photo-sensitive glasses, the change in the electronic structure of the centers plays an essential role $^{2)}$. Therefore, characterization of radiationinduced centers in glasses is one of the current and important problems in glass technology as well as in glass science. The information on the the centers associated with optically active elements in oxide glasses has accumulated until now $^{3}$. Our knowledge is, however, still insufficient to establish a comprehensive understanding of the characteristics of these centers on the basis of the periodic table of elements, which is one of our final targets.

In this paper, paramagnetic centers primarily localized on a phosphorus ion are examined. Although phosphorus-related paramagnetic centers have attracted much attention of glass scientists so far, the structural models and radiochemical reaction schemes proposed in earlier studies $^{4), 5)}$ are rather qualitative and of poor consistency. Such a situation is particularly true for the centers primarily localized on a phosphorus ion. In order to propose a faithful structural model of the centers and reaction mechanism involving the formation and conversion of centers, the authors have undertaken to reexamine radiation-induced paramagnetic centers localized on a phosphorus ion in binary metaphosphate glasses. The results obtained are compared with those of the centers associated with arsenic which has an electronic configuration analogous to that of phosphorus.

\section{Theoretical}

\subsection{ESR lineshape simulation of the centers in glass}

As has been clarified so far, the ESR lineshapes of paramagnetic centers in glassy hosts can be closely reproduced by the introduction of distribution in spin-Hamiltonian parameters to the expression of the lineshape for polycrystalline hosts. The site-to-site fluctuation of the local environment around the centers in glass is the structural origin of the distribution of the parameters.

In principle, all the relevant parameters fluctuate. In the case of some centers, however, the number of parameters which independently fluctuate each other can be reduced on the basis of the consideration about the chemical bonding of the center ${ }^{6,7)}$. Following the simulation of the centers associated with $\mathrm{As}^{8,9)}$ and $\mathrm{Si}^{10)}$ in which the unpaired electron is primarily localized on an NWF, the authors take into consideration only one fluctuating ESR parameter, isotropic component $\left(A_{\text {iso }}\right)$ of hyperfine (hf) tensor, $\tilde{\boldsymbol{A}}$. Then, the lineshape function, $S_{\mathbf{g}}(H)$, of the centers in glass is given by Eq. ( 1$)$;

$$
S_{\mathrm{g}}(H)=\sum_{i} \iint_{0}^{\pi / 2} P\left(A_{\mathrm{iso}}\right) f\left(H-H^{\prime}\right) \sin \theta \mathrm{d} \theta d A_{\text {iso }}
$$

where $P\left(A_{\text {iso }}\right)$ and $f$ are a Gaussian type distribution function of $A_{\text {iso }}$ and a Gaussian type convolution function which introduces the linewidth for a single crystal, respectively. The suffix $i$ denotes the expected transitions. The stable isotope of phosphorus is only ${ }^{31} \mathrm{P}$ with a half nuclear spin. Thus, the resonance field $H^{\prime}$ is calculated from the solution to the following spin-Hamiltonian :

$$
\mathscr{L}=\boldsymbol{\beta} \cdot \boldsymbol{S} \cdot \tilde{\boldsymbol{g}} \cdot \boldsymbol{H}+\boldsymbol{I} \cdot \tilde{\boldsymbol{A}} \cdot \boldsymbol{S}
$$

Here, the symbols have their usual meanings. In the case of the centers which are analyzed here, the magnitude of the hf coupling (latter term) reaches ca. $1 / 3$ of electronic Zeeman energy 
(former) for X-band ( $\nu \cong 10 \mathrm{GHz}$ ) measurements. Therefore, a new solution ${ }^{11,12)}$ to the Hamiltonian is adopted for calculating $H^{\prime}$ in place of the conventional solution ${ }^{13)}$ obtained by higher field approximation. This new solution has a wide applicability ${ }^{14}$ to the centers which can be described by Eq. ( 2 ) because there is no limitation in the relative magnitude between hf interaction and electronic Zeeman energy. The apparent lineshape of the centers shows that both $\widetilde{\boldsymbol{g}}$ - and $\tilde{\boldsymbol{A}}$-tensors have axial symmetry expressed by

$$
\tilde{\boldsymbol{g}}=\left(\begin{array}{ccc}
g_{\|} & 0 & 0 \\
0 & g_{\perp} & 0 \\
0 & 0 & g_{\perp}
\end{array}\right), \tilde{\boldsymbol{A}}=\left(\begin{array}{ccc}
\mathrm{A} & 0 & 0 \\
0 & \mathrm{~B} & 0 \\
0 & 0 & \mathrm{~B}
\end{array}\right)
$$

The resonance fields for a pair of the $\mathrm{hf}$ absorptions are summarized in Table 1.

Table 1. Expected transitions for $\mathrm{P}^{4+}$ centers in X-band ESR measurement.

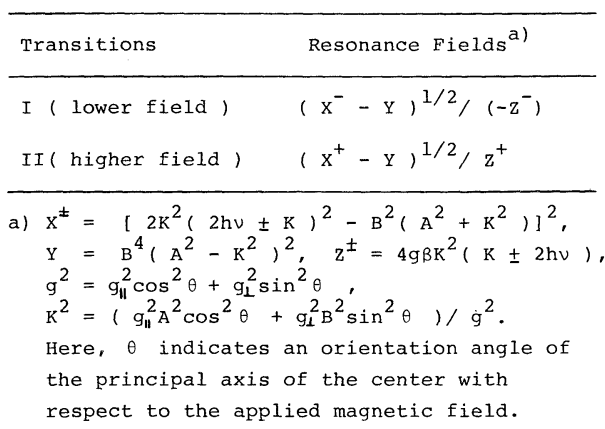

In the practical simulation procedures, the mean value of ESR parameters and dispersion width of $P\left(A_{\text {iso }}\right)$ were chosen so as to fit the calculated trace to the observed one. The evaluation of Eq. (1) was carried out on a computer.

\subsection{Structural interpretation of fluctuation in} $A_{\text {iso }}$

The fluctuation of ESR parameters indispensable for simulating "glassy spectrum" arises from the existence of a continuous random variation in the local environments surrounding any particular paramagnetic site. According to $\mathrm{Mackey}^{2)}$ and Griscom et al. ${ }^{101}$, the fluctuation in $A_{\text {iso }}$ is assumed to originate from the distribution of the bond angle associated with the center. This assumption is justified as follows; the authors have proposed an empirical rule ${ }^{7), 15}$ that structural distortion in glass, which produces the structural fluctuation, tends to concentrate on most deformable, weak points. It is a well-known fact that the force constant of bending vibration is fairly smaller than that of stretching mode. The assump- tion is justified by the application of the empirical rule to the above fact.

From the above assumption, the fluctuation of $A_{\text {iso }}$ may be related to that of the (defect)-P-O bond angle $\rho$ : According to a theory ${ }^{10), 16)}$ based on hybrid orbitals, $A_{\text {iso }}$ is connected with $\rho$ by a simple equation. When an unpaired electron occupies an $\mathrm{sp}^{\mathrm{n}}$ hybrid orbital in the center with $C_{3 \mathrm{v}}$ symmetry, Eq. (4) expresses the relation between $A_{\text {iso }}$ and $\rho$;

$$
\tan \rho=\left(-2\left(1+\frac{A_{\text {an }}}{A_{\mathrm{p}}} \cdot \frac{A_{\mathrm{s}}}{A_{\text {iso }}}\right)\right)^{1 / 2}
$$

where $A_{s}$ and $A_{\mathrm{p}}$ are the isotropic and anisotropic component of $\tilde{\boldsymbol{A}}$-tensor in a free space. The isotropic $\left(A_{\text {iso }}\right)$ and the anisotropic $\left(A_{\text {an }}\right)$ component of $\tilde{\boldsymbol{A}}$ are given by Eqs. (5) and (6), respectively ;

$$
\begin{aligned}
& A_{\text {iso }}=\frac{\mathrm{A}+2 \mathrm{~B}}{3} \\
& A_{\text {an }}=\frac{\mathrm{A}-\mathrm{B}}{3}
\end{aligned}
$$

Then, the probability distribution in $A_{\text {iso }}$, $P\left(A_{\text {iso }}\right)$, can be converted into a distribution in $\rho$ by

$$
P(\rho)=P\left(A_{\text {iso }}\right) /\left|\frac{\partial \rho}{\partial A_{\text {iso }}}\right|
$$

Since the distribution width of O-NWF-O angle is extremely small compared with that of NWF-ONWF, the evaluation of this quantity is very difficult. Therefore, Eq. ( 7 ) provides a novel information on the structural distribution in glass network.

\section{1 Sample preparation}

\section{Experimental}

Sample glasses were prepared from reagent grade $\mathrm{BeO}, \mathrm{NH}_{4} \mathrm{H}_{2} \mathrm{PO}_{4}$ and $\mathrm{Ce}\left(\mathrm{NO}_{3}\right)_{3} \cdot 6 \mathrm{H}_{2} \mathrm{O}$ and extra pure $\mathrm{NaPO}_{3}$.

The batches of sodium phosphates were melted for $2 \mathrm{~h}$ under an ambient atmosphere in a platinum crucible at $800^{\circ} \mathrm{C}$.

Beryllium phosphates were melted at $1400^{\circ} \mathrm{C}$ for $2 \mathrm{~h}$ in alumina crucibles because phosphate melts severely corrode platinum at higher temperatures $\left(>1300^{\circ} \mathrm{C}\right)^{17)}$. The melts were poured on a carbon plate and cooled in air. No annealing was made after quenching the melt. Each polycrystalline form was obtained by the crystallization of mother glass, being identified by powder X-ray diffraction method.

\subsection{Gamma-irradiation}

The specimens were coarsely crushed and 
placed in fused silica glass tubes. Each tube was sealed under degassing for low temperature gamma irradiation and ESR measurement.

After recording their ESR blank level, the sealed specimens were subjected to $\gamma$-irradiation from a ${ }^{60} \mathrm{Co}$ source with the dose of $10^{6} \mathrm{Rad}$ at $77 \mathrm{~K}$ or at an ambient temperature.

\section{3 ESR measurements}

$\mathrm{X}$-band ESR measurements were carried out at $77 \mathrm{~K}$ or $300 \mathrm{~K}$ with a JEOL model ME-3X and/or $\mathrm{PE}-3 \mathrm{X}$ spectrometer. The applied magnetic fields and the microwave frequency were calibrated by a proton NMR field marker and a cavity wave meter, respectively. During the measurements, the resonant cavity was purged with $\mathrm{N}_{2}$ gas to eliminate the background signal due to $\mathrm{O}_{2}$ in air ${ }^{18}$.

The $\mathrm{P}^{4+}$ centers which are analyzed in this study have a large participation of 3 s component of phosphorus to the singly occupied molecular orbital (SOMO). This nature may make these centers extremely sensitive to power saturation compared with a familiar hole trapped center on a oxygen or oxygens whose SOMO is exclusively composed of $2 \mathrm{p}$ a. o. " because spin-lattice relaxation process is supposed to be controlled by spin-orbital coupling $\boldsymbol{L} \cdot \boldsymbol{S}$ (s electron has no orbital angular momentum $\boldsymbol{L})^{19}$. From the plots of the signal intensity against the square root of incident microwave power, a saturation phenomenon was distinctly observed at the level beyond $\approx 10^{-1}$ $\mathrm{mW}$. Therefore, microwave power of $10^{-2} \mathrm{~mW}$ was adopted in the course of the experiment. Such a lower output of the microwave was generated from a gunn-type oscillator.

\section{Results and discussion}

\subsection{Centers in beryllium metaphosphate glass}

Figure 1 shows the X-band ESR spectra of polycrystalline and glassy $\mathrm{Be}\left(\mathrm{PO}_{3}\right)_{2}$ irradiated by $\gamma$-rays at 77 or $300 \mathrm{~K}$. A pair of absorptions with the separation of ca. $120 \mathrm{mT}$ ( 1 Tesla $=10000$ Gauss) was seen in both hosts irradiated by $\gamma$-rays at $77 \mathrm{~K}$ in addition to an hf doublet of atomic hydrogen $\left(\mathrm{H}^{0}\right)^{20)}$ and the well-known phosphorus-oxygen hole center ( $\mathrm{POHC})^{21,22)}$, which is too intense to be drawn completely in the figure. Judging from its multiplicity (being doublet) and splitting width (reaching ca. $120 \mathrm{mT}$ ), this pair should be assigned to a hyperfine structure ( $\mathrm{hfs}$ ) due to a ${ }^{31} \mathrm{P}$ nucleus $(\mathrm{I}=1 / 2, \mathrm{~N} . \mathrm{A} .=100 \%)$,

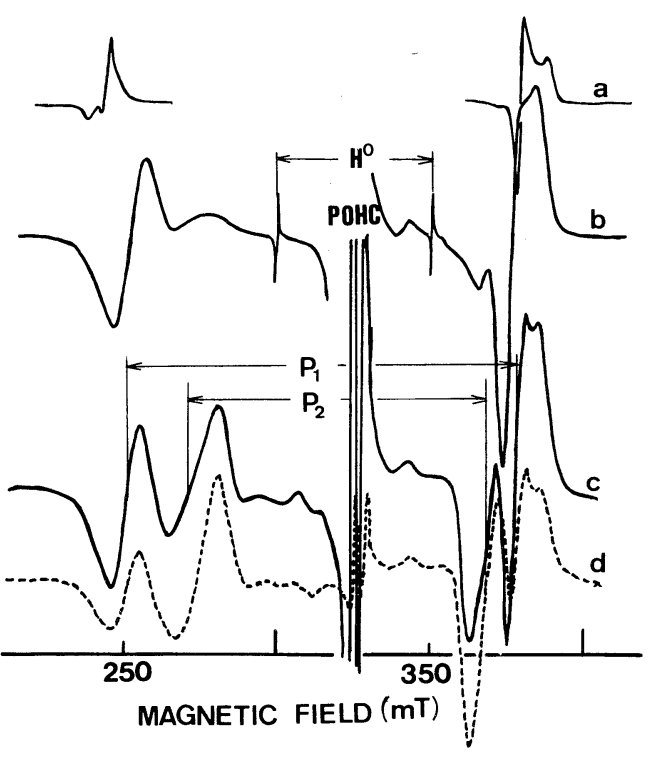

Fig. 1. X-band ESR spectra of $\gamma$-irradiated $\mathrm{Be}\left(\mathrm{PO}_{3}\right)_{2}$. All the measurements were conducted at $77 \mathrm{~K}$. For simplicity, the intense hf doublet of the phosphorusoxygen hole center (POHC) in the central region was omitted for traces a and b. (a)As-irradiated (77 K) polycrystalline $\mathrm{Be}\left(\mathrm{PO}_{3}\right)_{2}$, (b) As-irradiated (77 K) glassy $\mathrm{Be}\left(\mathrm{PO}_{3}\right)_{2}$. A sharp doublet with the sepration of $50 \mathrm{mT}$ is due to atomic hydrogen $\mathrm{H}^{0}(\mathrm{I}=\mathrm{S}=1 / 2)$, (c) Glassy $\mathrm{Be}\left(\mathrm{PO}_{3}\right)_{2} \gamma$-irradiated at $300 \mathrm{~K}$ for $2 \mathrm{~h}$, (d) Specimen $\mathrm{c}$ illuminated with a Xe-lamp at $77 \mathrm{~K}$. The spectrometer was operated with the same sensitivity in recording traces $\mathrm{c}$ and $\mathrm{d}$.

the unpaired electron primarily being localized on a phosphorus ion. This hfs is hereafter abbreviated as $\mathrm{P}_{1}$ signal. The ESR parameters of $\mathrm{P}_{1}$, which were determined by the simulation of the observed spectrum, are summarized in Table 2. The dotted line in Fig. 2 represents the best fitted simulation.

The glass specimen irradiated at $300 \mathrm{~K}$ gave another hf doublet besides $\mathrm{P}_{1}$. This hf absorption has a separation smaller $(\approx 92 \mathrm{mT})$ than that $(\approx 120 \mathrm{mT})$ of $\mathrm{P}_{1}$, being termed as $\mathrm{P}_{2}$. The $\mathrm{P}_{2}$

Table 2. ESR parameters employed in lineshape simulation of $\mathrm{P}_{1}$ signal in as-irradiated $(77 \mathrm{~K}) \mathrm{Be}\left(\mathrm{PO}_{3}\right)_{2}$ glass and $\mathrm{P}_{\gamma}$ signal in $\mathrm{NaPO}_{3}$ glass fully stabilized at $300 \mathrm{~K}$ after $\gamma$-irradiation at $77 \mathrm{~K}$.

\begin{tabular}{llllll}
\hline Signals & $g_{\| 1}$ & $g_{\perp}$ & $A_{\text {iso }}(\mathrm{mT})$ & $\mathrm{A}_{\text {an }}(\mathrm{mT})$ & $\left.\sigma_{\text {iso }}(\mathrm{mT})^{\mathrm{a}}\right)$ \\
\hline $\mathrm{P}_{1}$ & 2.017 & 1.993 & 126.3 & 6.6 & 5.5 \\
$\mathrm{P}_{\gamma}$ & 2.005 & 2.006 & 75.3 & 5.8 & 5.8 \\
\hline
\end{tabular}

a) A Gaussian distribution function was introduced for isotropic hf coupling ( $\mathrm{A}_{\text {iso }}$ ) in order to fit the experimental lineshape closely. $\sigma_{i s o}$ is the assumed standard deviation of $\mathrm{A}_{\text {iso. }}$. 


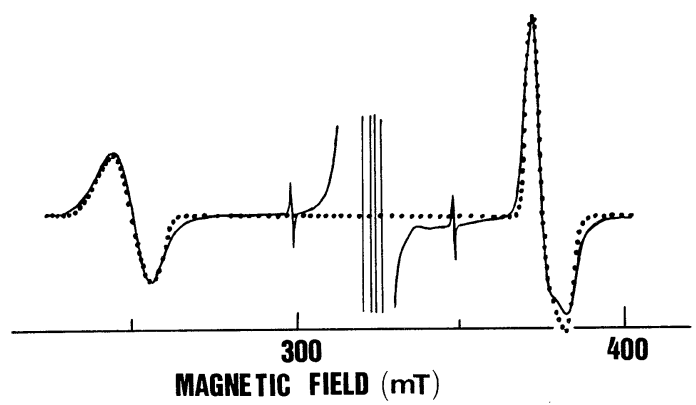

Fig. 2. X-band ESR spectrum of $\mathrm{Be}\left(\mathrm{PO}_{3}\right)_{2}$ glass measured at $77 \mathrm{~K}$ after $\gamma$-irradiation at $77 \mathrm{~K}$ without an intervening warm-up. The dotted trace is a simulation curve based on the parameters listed in Table 2.

Table 3. Spin densities of $\mathrm{P}^{4+}$ centers on a phosphorus.

\begin{tabular}{|c|c|c|c|c|}
\hline Centers & P $3 s(8)^{a)}$ & $3 p(8)$ & $3 p / 3 s$ & References \\
\hline $\mathrm{P}_{1}$ in $\mathrm{C}-\mathrm{Be}\left(\mathrm{PO}_{3}\right)_{2}$ & 34 & 46 & 1.4 & This work \\
\hline $\mathrm{P}_{1}$ in $\mathrm{g}-\mathrm{Be}\left(\mathrm{PO}_{3}\right)_{2}$ & 32 & 59 & 1.9 & $"$ \\
\hline $\mathrm{P}_{2}$ in $\mathrm{g}-\mathrm{Be}\left(\mathrm{PO}_{3}\right)_{2}$ & $22^{\mathrm{b})}$ & - & - & $"$ \\
\hline $\mathrm{P}_{\alpha}$ in $\mathrm{c}-\mathrm{NaPO}_{3}$ & 25 & 51 & 2.1 & This work \\
\hline $\mathrm{P}_{\alpha}$ in $\mathrm{g}-\mathrm{NaPO}_{3}$ & 23 & - & - & $"$ \\
\hline $\mathrm{P}_{\beta}$ in $\mathrm{g}-\mathrm{NaPO}_{3}$ & 16 & - & 一 & $"$ \\
\hline $\mathrm{P}_{Y}$ in $\mathrm{g}-\mathrm{NaPO}_{3}$ & 19 & 53 & 2.8 & $"$ \\
\hline $\mathrm{P}^{4+}$ in $\alpha-\mathrm{SiO}_{2}$ & 28 & 60 & 1.9 & 25) \\
\hline $\mathrm{PO}_{4}^{4-}$ in $\mathrm{C}-\mathrm{Be}_{2} \mathrm{SiO}_{4}$ & 29 & 39 & 1.4 & $31,32)$ \\
\hline $\mathrm{PO}_{3}^{2-}$ in $\mathrm{MgHPO}_{3} \cdot 6 \mathrm{H}_{2} \mathrm{O}$ & 17 & 52 & 3.1 & 33) \\
\hline $\mathrm{PO}_{3}^{2-}$ in $\mathrm{Na}_{2} \mathrm{HPO}_{3} \cdot 5 \mathrm{H}_{2} \mathrm{O}$ & 15 & 49 & 3.3 & 34) \\
\hline
\end{tabular}

a) Atomic parameters of ${ }^{31} \mathrm{P}$ in free space; ${ }^{35)}$

$A_{S}(3 s)=399.2 \mathrm{mT}, A_{p}(3 p)=11.0 \mathrm{mT}$.

b) The $A_{i s o}$ was calculated from Breit-Rabi solution, 36,37 because of close overlapping with $\mathrm{P}_{1}$.

also appeared by warming as-irradiated ( $77 \mathrm{~K}$ ) glass up to room or higher temperatures. During the annealing, the intensity of $\mathrm{P}_{2}$ relative to $\mathrm{P}_{1}$ monotonically increased with the duration of time. Thus, as-induced $\mathrm{P}_{1}$ center characterized by the larger separation is found to relax into $\mathrm{P}_{2}$ center characterized by the smaller one.

Here, the coordination geometries responsible for $P_{1}$ and $P_{2}$ centers will be considered on the basis of the spin densities on a phosphorus ion (Table 3). There have accumulated studies on radiation-induced paramagnetic centers mainly localized on a phosphorus in crystalline phosphorus compounds ${ }^{23)}$. From the results of these studies the coordination structures of the centers are classified into the following two types: One is a $\mathrm{P}^{4+}$ with threefold coordination in which the unpaired electron occupies one of four $\mathrm{sp}^{3}$ hybridized orbitals. This center is an analogue of a well-known $\mathrm{Si} \mathrm{E} \mathrm{E}^{\prime}$-center ${ }^{24)}$, being frequently seen in irradiated metal (M) hydrogen orthophosphites $\left(\mathrm{MHPO}_{3}\right)$. Another is a fourfold coordinated $\mathrm{P}^{4+}$. The excess electron occupies an anti-bonding sigma molecular orbital, which is primarily distributed on a $\mathrm{P}-\mathrm{O}$ bond, or a nonbonding orbital which points in the direction of the bisector of certain $\mathrm{O}-\mathrm{P}-\mathrm{O}$ bond angle. In phosphorus-doped $\alpha$-quartz, $\left(\mathrm{PO}_{4}\right)^{0}$ center $^{25)}$ is a typical example. These two centers can be discriminated by the comparison of the magnitude of $\mathrm{P}$ $3 \mathrm{~s}$-character and/or the ratio of hybridization, $\mathrm{p} / \mathrm{s}$, in the SOMO. The threefold-coordinated center has a smaller $3 \mathrm{~s}$-character (15-17\%) and a larger $\mathrm{p} / \mathrm{s}$ ratio, which is about 3 as expected from its structural model, compared with those of the fourfold-coordinated center $(28-29 \%, 1.4-1.9)$. By applying the above criterion to $\mathrm{P}_{1}$ and $\mathrm{P}_{2}$, we can conclude that the former and the latter are assigned to the fourfold- and the threefoldcoordinated $\mathrm{P}^{4+}$, respectively. On the basis of this assignment, the radiochemical reaction involuing the structural relaxation of as-induced center are summarized in Fig. 3.

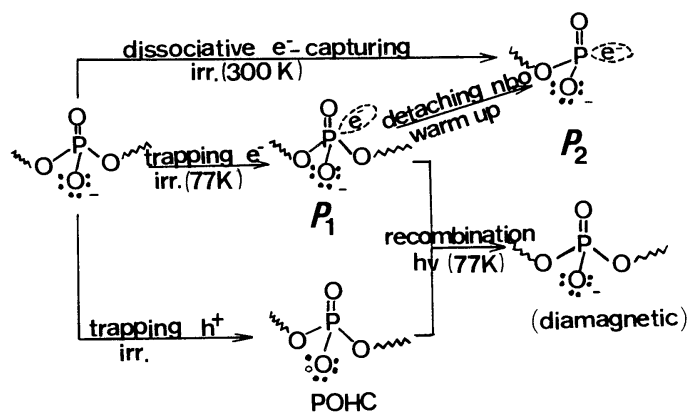

Fig. 3. A model for the formation of $\mathrm{P}_{1}$ center and $\mathrm{POHC}$ and their conversion upon thermal annealing or light illumination. The symbol, $m$ stands for condensed phosphate chain. The unpaired electron and the lobe of its trapping orbital are expressed by the symbol $\mathrm{e}^{-}$and the dotted loop, respectively.

The driving force of this structural relaxation is considered to be an electrostatic repulsion between an excess electron and lone pair electrons on the oxygens directly attaching to the phosphorus. On warming the as-irradiated glasses, the fourfold-coordinated $\mathrm{P}^{4+}$ center is converted into the threefold-coordinated one, detaching an oxygen from its coordination sphere. Then, the local electroneutrality around the phosphorus ion is established. These models are further substantiated by the results (Fig. 1 (c) and (d)) of illumination of the specimen with a Xe-lamp: 
The sample was irradiated by $\gamma$-rays at $300 \mathrm{~K}$. In this sample, the intensity of $\mathrm{P}_{2}$ is comparable to that of $P_{1}$ as shown in Fig. 1(c). The intensity of $\mathrm{P}_{1}$ drastically decreased in concert with $\mathrm{POHC}$ on illumination, while $\mathrm{P}_{2}$ remains almost unchanged

(trace $d$ ). This fact is well explained by the recombination of a trapped electron on $\mathrm{P}_{1}$ and a trapped hole on $\mathrm{POHC}$. Since this reaction is, of course, restricted to the centers with an excess charge, no $\mathrm{P}_{2}$ center which satisfies the requirement of local electroneutrality is considered to be involved.

\section{2 Centers in other metaphosphate glasses}

The formation of a fourfold-coordinated $\mathrm{P}^{4+}$ center and its thermal relaxation into an $E^{\prime}$-type threefold-coordinated $\mathrm{P}^{4+}$ center, were observed commonly in all the alkali and alkaline earth metaphosphate glasses examined ( $\mathrm{Na}, \mathrm{Be}, \mathrm{Mg}$, $\mathrm{Ca}$, and $\mathrm{Ba})$. For instance, ESR spectrum of as-irradiated $(77 \mathrm{~K}) \mathrm{NaPO}_{3}$ glass is shown in Fig. 4 together with that of its polycrystalline form. Two sets of an hf doublet due to a ${ }^{31} \mathrm{P}$ nucleus are seen in the glassy host. Each pair is abbreviated as $\mathrm{P}_{\alpha}$ or as $\mathrm{P}_{\beta}$. The intensity of $\mathrm{P}_{\beta}$ relative to $\mathrm{P}_{\alpha}$ was almost unchanged in the glass doped with $\mathrm{Ce}^{3+}$ which is an effective hole scavenger ${ }^{26,27)}$. Therefore, both centers are ascribed to electron-trapping defect centers. By the application of the criterion to these two centers, it is deduced that $\mathrm{P}_{\alpha}$ and $\mathrm{P}_{\beta}$ are assigned to four and threefold-coordinated $\mathrm{P}^{4+}$ centers, respectively*. The experiment of isochronal

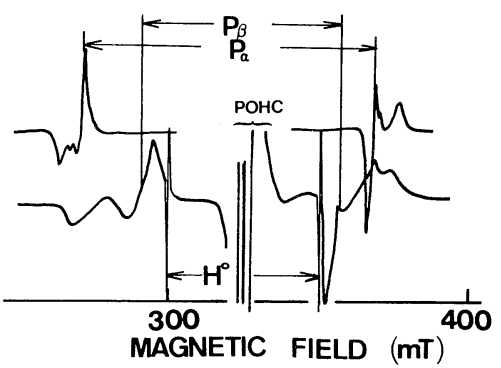

Fig. 4. ESR spectra of $\mathrm{NaPO}_{3}$ irradiated by $\gamma$-rays at $77 \mathrm{~K}$. Top: Polycrystalline, Bottom : Glassy $\mathrm{NaPO}_{3}$. All the measurements were conducted at $77 \mathrm{~K}$ without accompanying a warm-up of irradiated specimens.

\footnotetext{
* In a previous study ${ }^{5)}$, the composite of $\mathrm{P}_{\alpha}$ and $\mathrm{P}_{\beta}$ was ascribed to one center with axial symmetry from an apparent similarity of experimental and theoretical lineshape. Inadequacy of this model is obvious from the face that $\mathrm{P} 3 \mathrm{p}$ character evaluated on the basis of this model exceeds $100 \%$ (reaches $130 \%$ !). Therefore, we regarded $\mathrm{P}_{\alpha}$ and $\mathrm{P}_{\beta}$ as being due to two centers.
}
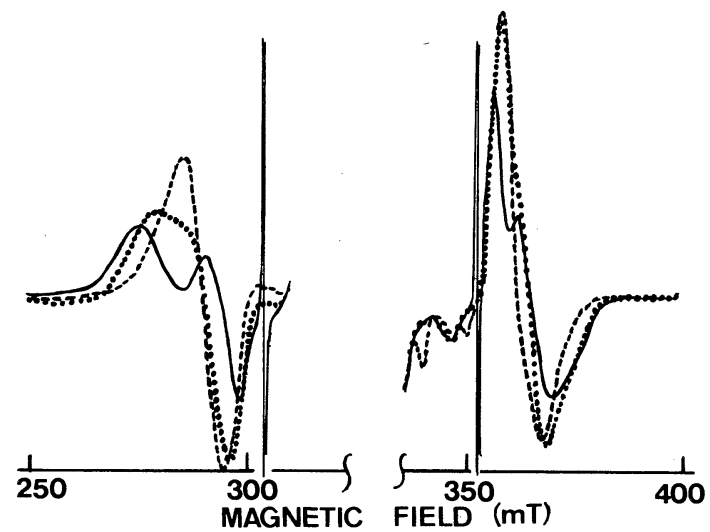

Fig. 5. Change in ESR lineshape of the hyperfine doublets due to a phosphorus nucleus upon thermal annealing of as-irradiated $(77 \mathrm{~K}) \mathrm{NaPO}_{3}$ glass. The measurements were all made with the same sensitivity at $77 \mathrm{~K}$ following $10 \mathrm{~min}$-anneals at each temperture. - : Before annealing, $\cdots: 0^{\circ} \mathrm{C}, \cdots: 100^{\circ} \mathrm{C}$.

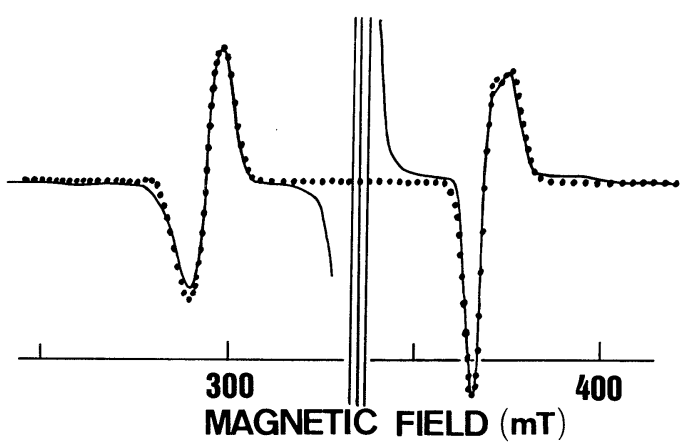

Fig. 6. X-band ESR spectrum of $\mathrm{NaPO}_{3}$ glass fully stabilized at $300 \mathrm{~K}$ after $\gamma$-irradiation at $77 \mathrm{~K}$. The dotted trace is a simulation of the center primarily localized on a phosphorus ion, based on parameters listed in Table 2.

annealing of as-irradiated glass revealed that both are converted into a new center, $\mathrm{P}_{\gamma}$, as shown in Fig. 5. The resulting $\mathrm{P}_{\gamma}$ center is an $\mathrm{E}^{\prime}$-analogue. This conclusion is obtained from both the magnitudes of its s-character and $\mathrm{p} / \mathrm{s}$ ratio (see Tables 2 and 3), which were evaluated through the lineshape simulation of the observed spectrum

(Fig. 6).

The fluctuation of the (defect)-P-O anglederived from Eq. ( 5 ) is also shown in Fig. 7. The half width of the angle is only $0.7^{\circ}$. This surprisingly small fluctuation is not restricted to the centers primarily localized on a phosphorus ion but rather a common characteristic of all the centers localized on an NWF which have been reported so $\mathrm{far}^{8,10), 28)}$. This is in a sharp contrast 


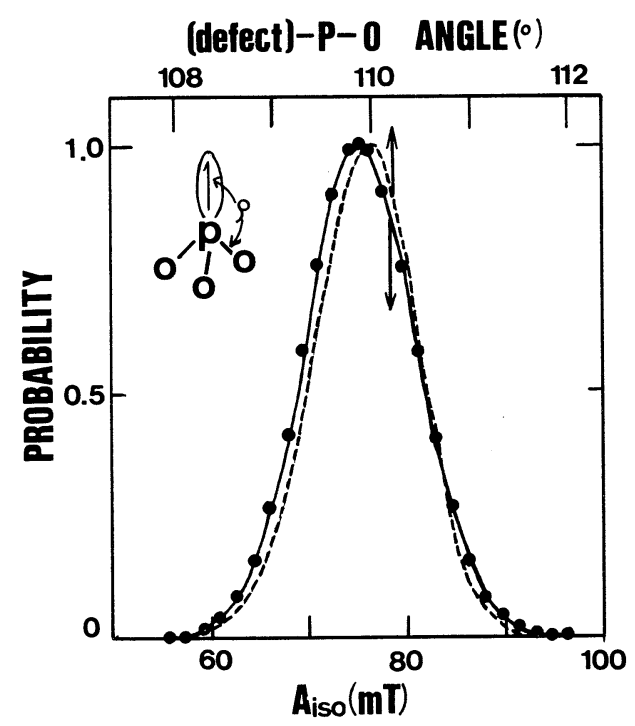

Fig. 7. Distribution of $A_{\text {iso }}$ values introduced in the simulation of Fig. 6 and fluctuation of (defect)-P-O bond angle derived from Eq. ( 7 ) in the text.

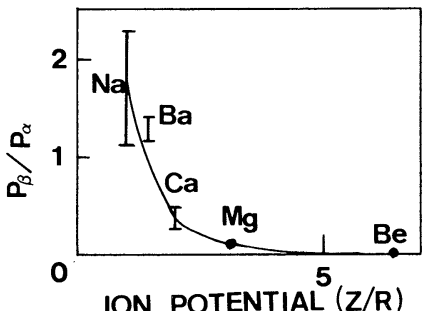

Fig. 8. Relation between intensity of $\mathrm{P}_{\beta}$ relative to $\mathrm{P}_{\alpha}$ in as-irradiated $(77 \mathrm{~K})$ metaphosphate glasses and ion potential of counter cation. The peak-to-peak height of each lower field absorption was adopted as a measure of the signal intensity.

with the fluctuation of NWF-O-NWF angle, which generally reaches an order of ten degree ${ }^{29}$. On the other hand, only $\mathrm{P}_{\alpha}$ center is seen in the polycrystalline host. The coexistence of $\mathrm{P}_{\alpha}$ and $\mathrm{P}_{\beta}$ center was commonly observed in as-irradiated metaphosphate glasses except $B e$ system, the intensity of $\mathrm{P}_{\beta}$ relative to $\mathrm{P}_{\alpha}$ sharply decreasing with the ion potential $Z / R(Z$ : valence, $R$ : ionic radius) of the counter cation (Fig. 8 ).

The precursor of $\mathrm{P}_{\beta}$ center is ambiguous, while that of $\mathrm{P}_{\alpha}$ is considered to be a $\mathrm{PO}_{4}^{2-}$ group. One plausible candidate of the precursor of $\mathrm{P}_{\beta}$ is a positively charged phosphorus ion which is coordinated by only three oxygens, i. e., the resulting center $\mathrm{P}_{\beta}$ can be regarded as an electron trapped at the vacancy of a non-bridging oxygen (not bridging oxygen because a strong interaction with only one $\mathrm{P}$ nucleus was observed). Another possible precursor is a $\mathrm{PO}_{4}^{2-}$ having a highly strained $\mathrm{P}-\mathrm{O}$ bond, which breaks under irradiation and subsequently traps an electron (dissociative electron capture). The existence of highly strained bond in glass was suggested by Griscom $^{1,30)}$, who imagined it in accounting for the formation of $\mathrm{E}^{\prime}$-center in $\mathrm{SiO}_{2}$ glass.

At present, we have no decisive data strongly substantiating either model.

\section{Summary}

In this paper paramagnetic centers primarily localized on a phosphorus ion in $\gamma$-irradiated glassy and polycrystalline metaphosphates were investigated with ESR. A P ${ }^{4+}$ having fourfold coordination was observed commonly in the asirradiated $(77 \quad \mathrm{~K})$ glassy and polycrystalline hosts, being considered to originate from a $\mathrm{PO}_{4}^{2-}$ group on trapping an electron. On thermal annealing of the as-irradiated glasses, the center was found to be converted into a $\mathrm{P}^{4+}$ with threefoldcoordination with $C_{3 \mathrm{v}}$ symmetry, detaching an oxygen from its coordination sphere. The driving force of such a structural relaxation is considered to be electrostatic repulsion between an excess electron and lone pair electrons on the oxygens directly attached to the phosphorus.

The results obtained in this work are almost identical with those of $\operatorname{arsenic}(\mathrm{V})$ in glass (radiation-induced defects in reduced phosphate glasses are to be published in the subsequent $\left.\operatorname{paper}^{38)}\right)$. The formation of the fourfold-coordinated center observed for both phosphorus and arsenic has never been known for typical NWF such as $\mathrm{Si}, \mathrm{B}$ and $\mathrm{Al}$. It is suggested that this result is a common characteristic of radiationinduced centers primarily localized on an NWF whose valence is greater than the coordination number; these ions would provide a coulombic trapping potential for an electron.

Acknowledgments The authors would like to thank Dr. D. L. Griscom of US Naval Research Laboratory (Washington, D. C. USA) for providing their paper prior to publication. One (H.H.) of the authors ackowledges a financial support from Saneyoshi Scholarship Foundation.

\section{References}

1) E. J. Friebele and D. L. Griscom, "Treatise on Materials Science and Technology”, Ed. M. Tomozawa and R. H. Doremus, Academic, NY (1979) Vol.17, p. 257351.

2) For instance, J. H. Mackey, J. W. Boss and M. Kopp, J. Chem. Phys, , 11, 205-12 (1970). 
3) For example, H. Kawazoe, H. Hosono and H. Imagawa, "Muki Amoruphasu Zairyo", Gakkai Shuppan Senta (1983) p. 67-81.

4) R. A. Weeks and P. J. Bray, J. Chem. Phys., 48, 5-13 (1968).

5) A. Hasegawa and M. Miura, Bull. Chem. Soc. Jpn., 40, 2553-58 (1967).

6) H. Imagawa, Phys. Stat. Sol., 30, 469-77 (1968).

7) H. Hosono, Y.Abe, H. Kawazoe and T. Kanazawa, Yogyo-Kyokai-Shi, 92, 350-59 (1984).

8) H. Imagawa, H. Hosono and H. Kawazoe, J. de Physique, 43, C-169-72 (1982).

9) H. Hosono, Y.Abe, H. Kawazoe and H. Imagawa, J. Non-Cryst. Solid. 63, 357-63 (1984).

10) D. L. Griscom, E. J. Friebele and G. H. Sigel, Jr., Solid State Commun., 15, 479-83 (1974).

11) H. Hosono, H. Kawazoe, J. Nishii and T. Kanazawa, J. Chem. Phys., 86, 161-64 (1982).

12) H. Kawazoe, H. Hosono and J. Nishii, J. Chem. Phys, 76, 3422-28 (1982).

13) P. C. Taylor, J. F. Baugher and H. M. Kriz, Chem. Rev., 75, 203-40 (1975).

14) H. Kawazoe, H. Hosono, J. Nishii and T. Kanazawa, $J$. Chem. Phys., 76, 3429-32 (1982).

15) H. Hosono, H. Kawazoe and T. Kanazawa, J. Non-Cryst. Solid., 34, 339-56 (1979).

16) A.R. Reinberg, J. Chem. Phys., 41, 850-55 (1964).

17) J.R. Van Wazer, "Phosphorus and Its Compounds", Interscience, NY (1958) p. 79-81.

18) R.S. Alger, "Electron Paramagnetic Resonance”, Interscience, NY (1968) chap. VI.

19) H. Hosono and Y.Abe, Proc. 24th Sym. Glass, Tokyo
(1983) p. 17-22.

20) J.A. Weil, J. Chem. Phys., 55, 4685-98 (1971).

21) G. O. Karapetyan and D. M. Yudin, Soriet Phys. -Solid State, 3, 2063-69 (1962).

22) R. Berger, G. Vignaud, R. Olazcuaga and M. Zahir, $J$. Non-Cryst. Solid., 54, 113-19 (1983).

23) P.Schipper, E. H. J. M. Hansen and H. M. Buck, "Topics in Phosphorus Chemistry", Interscience, NY, Vol. 9 (1976)p. 407-503.

24) R. A. Weeks, J. Appl. Phys., 27, 1376-81 (1956).

25) Y. Uchida, J. Isoya and J. A. Weil., J. Phys. Chem., 83, 3462-68 (1979).

26) J. S. Stroud, J. Chem. Phys., 37, 836-41 (1962).

27) R. Yokota and H. Imagawa, J. Phys. Soc. Jpn., 23, 1038-48 (1967).

28) K. L. Brower, Phys. Rev. B., 20, 1799-81 (1979).

29) R. L. Mozzi and B.E. Warren, J. Appl. Crystallogr., 3, 251-58 (1970).

30) D. L. Griscom, J. Non-Cryst. Solid., 40, 211-72 (1980).

31) H. Lozykowski, R. G. Wilson and F. Holuj, J. Chem. Phys., 51, 2309-15 (1969).

32) M. C. R. Symmons, J. Chem. Phys., 53, 857-58 (1970).

33) M.W. Hanna and L. J. Altman, J. Chem. Phys., 36, 1788-92 (1962).

34) M. C. R. Symmons, J. Chem. Soc. (A), 1970, 1998-2000.

35) D. L. Griscom, E. J. Friebele, K. J. Long and J. W. Fleming, J. Appl. Phys., 54, 3743-62 (1983).

36) G. Breit and I. I. Rabi, Phys. Rev., 38, 2082-83 (1931).

37) H. Hosono, J. Nishii, H. Kawazoe and T. Kanazawa, J. Phys. Chem., 84, 2316-19 (1980).

38) H. Hosono, Y.Abe and H. Kawazoe, J. Non-Cryst. Solid, in press. 